\title{
Liver Adenomatosis and Maturity-Onset Diabetes of the Young (MODY) Type 3 Due to HNF1A Mutation Not Previously Described
}

\author{
Maria del Carmen de Mingo Alemany, d, Francisca Moreno Macian ${ }^{\mathrm{a}}$, Sara Leon Carinena ${ }^{\mathrm{a}}$, \\ Begona Polo Miquel ${ }^{\mathrm{a}}$, Judith Perez Rojas ${ }^{\mathrm{b}}$, Juan Antonio Ceron Perez ${ }^{\mathrm{c}}$, \\ Carmen Rives Koninckx ${ }^{\mathrm{a}}$
}

\begin{abstract}
The term MODY (maturity-onset diabetes of the young) is allocated for a heterogeneous subgroup of different diseases, characterized by its autosomal dominant inheritance, with high penetrance and early expression in childhood and early youth. They are due to genetic defects in factors involved in the formation and function of pancreatic beta cells. MODY 3 diabetes is the most common in adults. Liver adenomatosis is a rare disease. Diagnosis requires the presence of more than ten adenomas in a healthy parenchyma, the absence of liver storage diseases, and nor prior steroid treatment. In 2002 Bluteau and colleagues find a common genetic defect for both pathologies, HNF1A gene's mutation. So far just five unrelated families with liver adenomatosis and MODY 3 diabetes due to HNF1A mutation have been reported. To our knowledge only four cases suffering from both pathologies under the age of 18 have been previously reported, and the mutation detected in all of them is P291fs in exon 4 of HNF1A gene. We present the case of a teenager with liver adenomatosis and MODY 3 diabetes, carrying a not previously described HNF1A gene's mutation.
\end{abstract}

Keywords: MODY 3; Adenomatosis; HNF1A mutation

\section{Introduction}

The term MODY (maturity-onset diabetes of the young) was originally allocated for diabetes in young, non-insulin depen-

\footnotetext{
Manuscript accepted for publication May 8, 2014

${ }^{a}$ Pediatrics, Hospital Universitari i Politecnic La Fe, Valencia, Spain

${ }^{b}$ Pathologic Anatomy, Hospital Universitari i Politecnic La Fe,

Valencia, Spain

${ }^{\mathrm{C}}$ Genetics, Hospital Universitari i Politecnic La Fe, Valencia, Spain

${ }^{\mathrm{d}}$ Corresponding Author: Maria del Carmen de Mingo Alemany,

Hospital Universitari i Politecnic La Fe, Pediatrics-Endocrinology,

Bulevar Sur s/n, 46026, Valencia, Spain.

Email: menchu25281@yahoo.es
}

doi: http://dx.doi.org/10.14740/jem218w dent people, while nowadays it is used for family diabetes with autosomal dominant inheritance pattern. It comprises a heterogeneous subgroup of different diseases, characterized by its autosomal dominant inheritance, with high penetrance and early expression in childhood and early youth (usually before 25 years of age). They are due to genetic defects in factors involved in the formation and function of pancreatic beta cells. There is no destruction of pancreatic beta cells, and the antibodies that confront them are negative [1].

Up to date 11 subtypes of MODY diabetes have been described corresponding to mutations in 11 different genes, some of which encode enzymes, and others encode transcription factors of the pancreatic beta cell [2].

MODY 3 diabetes is the most common in adults and is often associated with dyslipidemia and hypertension [1]. These patients have a low prevalence of obesity and are very sensitive to treatment with both, insulin and sulfonylurea [3].

MODY 3 diabetes has a high penetrance and an autosomal dominant inheritance pattern. It is due to mutations in HNF1A gene (22q24.31), also called TCF1, which encodes the hepatic nuclear factor 1 alpha, which regulates the transcription of the insulin gene. It is expressed in liver, kidney, bowel and pancreatic islets $[1,3,4]$.

Liver adenomatosis is a rare disease. Diagnosis requires the presence of more than ten adenomas in a healthy parenchyma, the absence of liver storage diseases, and nor prior steroid treatment. Adenomas are well defined and may have a full or partial capsule. It is a medical condition different from hepatocellular adenomas, although they both share similar histological features. Liver adenomatosis diagnosis is often incidental, although chronic non-specific abdominal pain can be present. Spontaneous tumor rupture causing intratumoral and/or intraperitoneal hemorrhage is a very uncommon complication. Adenomas exceptionally can become malignant [5].

Prevalence of hepatic adenomatosis is unknown. Familial and sporadic cases have been described. Etiology is unknown, although it has been found that $50 \%$ of adenomas are associated to a biallelic inactivation of HNF1A gene, either due to two somatic mutations ( $85 \%$ of cases) or the association in heterozygosity of both, a somatic and a germinal mutation $[5,6]$. In less than $10 \%$ of cases beta-catenin gene 


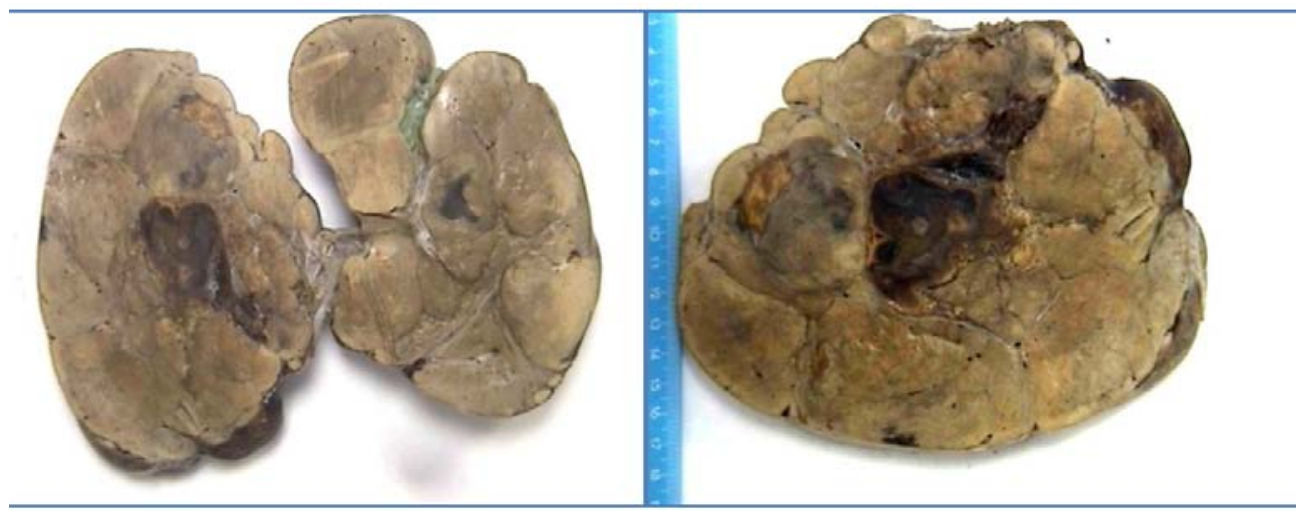

Figure 1. Macroscopic photo of part of tumor. Multinodular hepatic parenchyma, yellowish, with areas of central hemorrhage.

mutation has been detected [5].

The HNF1A role in hepatic tissue has not yet been clarified. Animal studies show that its complete inactivation in mice produces liver enlargement and hepatic dysfunction $[7,8]$. Experimental liver carcinogenesis in rats is associated with HNF1A impaired expression [9], suggesting that it could have a tumor suppressor gene role in the liver.

In 1978 Foster and colleagues first described a family in which there were four patients with diabetes mellitus and liver adenomatosis [10]. They suggested the possibility of an etiological link between both pathologies. But it was not until 2002 when Bluteau and colleagues find a common genetic defect for both pathologies, HNF1A gene's mutation [6].

So far just five unrelated families with liver adenomatosis and MODY 3 diabetes due to HNF1A mutation have been reported [11, 12]. To our knowledge only four cases suffering from both pathologies under the age of 18 have been previously reported.

Reznik and colleagues describe three patients from the same family, 15, 16 and 17 years old, with both pathologies, and another 14-year-old patient from a different family with the same clinical picture [11]. All these patients were under 18 and the mutation detected in HNF1A was P291fs in exon 4. Must previously described mutation in families with MODY 3 diabetes have been located in this codon [13-15].

We present the case of a teenager with liver adenomatosis and MODY 3 diabetes, carrying a not previously described HNF1A gene's mutation.

\section{Case Report}

A 15-year-old girl was diagnosed of liver adenomatosis in September 2012. She was suffering intermittent abdominal pain with progressive distention for 2 months and decided to consult Emergency Department. Physical examination revealed a mass at epigastric level that exceeded the middle line. Routine blood counts and serum biochemistry were performed, and a low hemoglobin level of $8.4 \mathrm{~g} / \mathrm{dL}$ was the only abnormality found. Abdominal ultrasound showed hepatomegaly with a predominant left lobe at the expense of multiple nodules growth of various sizes $(60-90 \mathrm{~mm})$, the majority iso- and hypo-echoic, in relation to the rest of the parenchyma. A progressive trend to anemia was detected in analytical tests. A transfusion of red blood cells was needed. Tumor markers (CEA, alfa-feto-proteine and neuron-specific

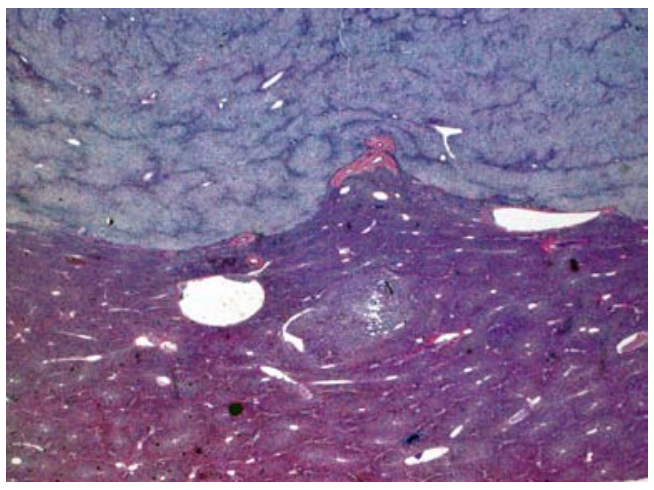

Figure 2. Hematoxylin and eosin stain.

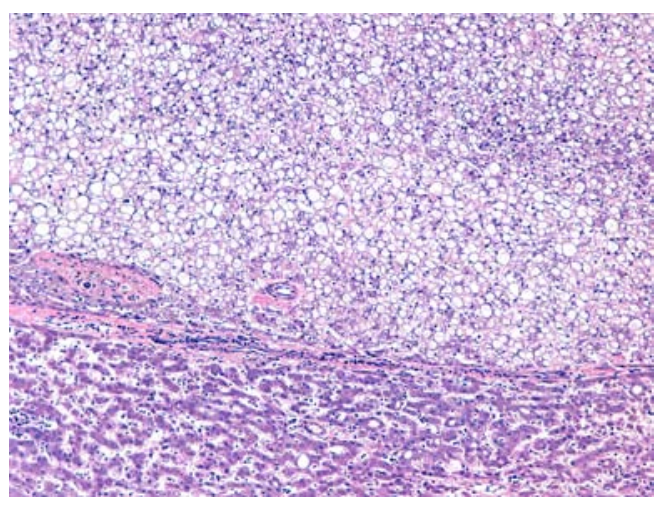

Figure 3. Hematoxylin and eosin stain. 


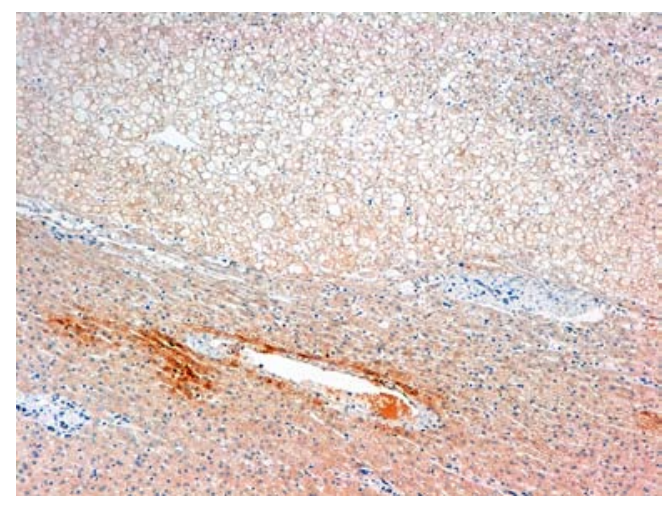

Figure 4. Glutamine sintetasa.

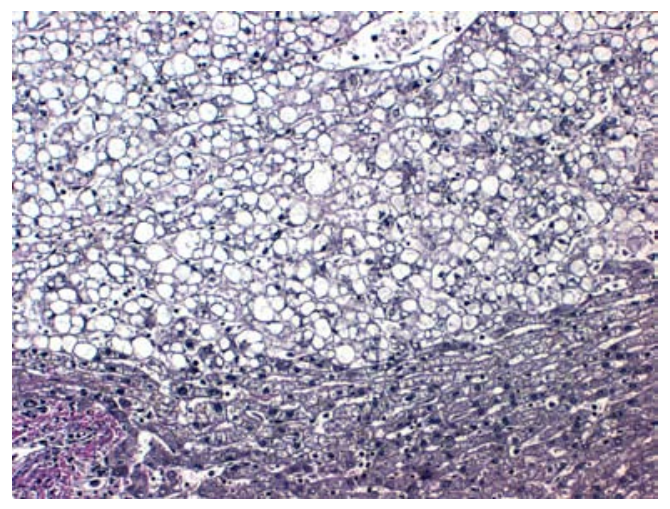

Figure 5. Reticulin fibers. enolase) were negative. MRI was also performed and showed multiple liver nodules of different sizes diffusely distributed in the parenchyma. The largest nodule was located in the left lobe and showed abundant hematic content. The findings were consistent with liver adenomatosis and intratumoral bleeding. Ultrasound-guided liver biopsy was performed; pathology was conclusive for hepatic adenomatosis, within unclassifiable adenomas. Nodullar cells showed no reactivity to amyloid A, periventricular mapping against glutamine synthetase was absent, beta-catenin had normal membrane expression and did not show nuclear over-expression or cytoplasmic. No loss of immunoreactivity to the protein carrier of fatty acid was detected.

No other cases of liver adenomatosis were reported in the family, but there was a family history of diabetes mellitus on the maternal side: mother, maternal grandmother and maternal uncle. The mother is currently being treated with metformin and repaglinide. This woman had three children, the first one died at 7 months of age, and the cause of the death was unknown.

In order to avoid the risk of spontaneous intraperitoneal bleeding a liver transplantation was carried out in December 2012 (Fig. 1-5). Five days later she required a second liver transplant due to vascular graft failure, thrombosis and bleeding.

One month after transplant, in the context of steroid treatment, she showed increasing glycemia. Her fasting glucemia was normal before transplant. Pharmacological diabetes was suspected and she was initially treated with subcutaneous insulin. Despite the decline of steroid treatment 3 months after transplantation she required high insulin doses with basal-bolus regimen (glargine insulin and aspart insulin). Antibodies that confront pancreatic islet were negative. Peptide $\mathrm{C}$ was $2.84 \mathrm{ng} / \mathrm{mL}$ (normal values in our laboratory $1-3 \mathrm{ng} / \mathrm{mL}$ ). Considering family history of diabetes mellitus in three generations and the association of liver adenomatosis we suspected MODY 3 diabetes. A genetic study of mutation in HNF1A gene was requested and the change c.1192C $>\mathrm{T}$ in heterozygosity was detected. This change results in a pre-mature stop codon. It is a not previously reported mutation, and due to its characteristics is probably pathogenic.

\section{Discussion}

Some healthy carriers of HNF1A mutations have been previously reported, as well as cases with isolated MODY 3 diabetes. But only few patients sharing both pathologies have been reported.

Although the exact prevalence of these conditions is unknown, MODY 3 diabetes is significantly more frequent than liver adenomatosis. The reason why some patients carrying mutations in HNF1A are asymptomatic or develop diabetes, or liver adenomatosis, is still unknown. Perhaps liver adenomatosis appears only after a second mutation in somatic tissue affecting the other allele, in patients that carry a germinal HNF1A mutation.

HNF1A gene is located on the long arm of chromosome 12. It comprises three functional domains: 1) The N-terminal, which is involved in proteins dimerization and includes exon 1.2) The domain responsible to DNA binding which includes exons 2 and 3. 3) The C-terminal involved in the trans-activation and includes exons 4 to 10 [16].

Mutations so far observed in HNF1A gene in patients with liver adenomatosis are frameshift or nonsense mutations in the coding sequence, or missense mutations in homedomain [6]. In contrast the mutations most frequently found in patients with diabetes MODY type 3 are missense mutations throughout the entire gene sequence [13]. Probably liver adenomatosis only develops in the presence of a severe HNF1A functional disturbance.

The identified mutation in our patient has not been previously described as pathogenic. This mutation generates a pre-mature stop codon, and probably this causes severe HNF1A damage, which could explain both pathologies expression in our patient.

Both MODY 3 diabetes and liver adenomatosis have a highly variable clinical expression [17, 18]. Patients with the 
same mutation may show different clinical pictures. This fact could rely on certain genetic and environmental factors that remain to be clarified.

Although liver adenomatosis is usually incidentally diagnosed, it can associate severe complications. For this reason, we agree with the authors who recommend performing non-invasive imaging tests in patients with MODY 3, with the intention of carrying out liver pathology screening [19]. We also think that these studies may help to establish the prevalence of liver adenomatosis in patients with MODY 3 diabetes that is the more frequent MODY diabetes. Besides these studies perhaps can also clarify what genetic and environmental factors are related to the highly variable clinical expression of MODY 3 and liver adenomatosis.

On the other hand there are also some authors who recommend performing an oral glucose tolerance test, or at least some diabetes mellitus screening, to patients already diagnosed of liver adenomatosis without known diabetes [19]. We think this would help to clarify the prevalence of patients with both pathologies.

Many patients with mutations in gene HNF1A gene have glucosuria before diabetes establishment because they have renal disturbance in the tubular re-absorption of glucose. We think that patients with liver adenomatosis and glycosuria who have a normal oral glucose tolerance test, should be followed up by an endocrinologist due to the possibility of developing diabetes.

Finally we consider a controversial issue whether the treatment with sulfonylurea would be indicated in our patient.

The incidence of micro-vascular complications in MODY 3 diabetes is similar to type 1 diabetes mellitus [20]. For this reason it is now recommended to start treatment as early as possible to maintain $\mathrm{HbAlc}$ rate below 7\%. Patients with MODY 3 have high sensibility to sulfonylurea, which can be even greater than in type 2 diabetes mellitus and can remain many years after diagnosis [3], although over the course of the disease, most patients (up to $74 \%$ ) will require insulin treatment to achieve better metabolic control [21]. The need to treat with insulin in a long term may be associated with a progressive decline in insulin secretion by the pancreatic beta cell in these patients [20].

Bibliographic references on the use of sulfonylurea in MODY 3 diabetes in children are scare, but the published results are favorable $[22,23]$. Sulfonylurea seems to have three advantages over insulin: greater therapeutic sensitivity, a decrease of hypoglycemia including severe hypoglycemia [24] and improvement in quality of life perceived by the patient entailing better treatment compliance [20].

We find that the use of sulfonylurea in our patient is controversial, since she has previously received two liver transplants, and after this treatment hyper-transaminasemia, cholestasis, jaundice and hepatitis have been described. Furthermore, this patient now has an excellent metabolic con- trol (last HbA1c 6\%) with subcutaneous insulin.

Since much remains unknown about the genetics of MODY 3 diabetes and liver adenomatosis, we believe the publication of clinical cases with these conditions is interesting, and may help to elucidate the etiology.

\section{Conflict of Interest}

There is no conflict of interest.

\section{Financial Support}

There is no financial support.

\section{References}

1. Fajans SS, Bell GI, Polonsky KS. Molecular mechanisms and clinical pathophysiology of maturity-onset diabetes of the young. N Engl J Med. 2001;345(13):971980.

2. Steck AK, Winter WE. Review on monogenic diabetes. Curr Opin Endocrinol Diabetes Obes. 2011;18(4):252258.

3. Pearson ER, Liddell WG, Shepherd M, Corrall RJ, Hattersley AT. Sensitivity to sulphonylureas in patients with hepatocyte nuclear factor-1alpha gene mutations: evidence for pharmacogenetics in diabetes. Diabet Med. 2000;17(7):543-545.

4. Casamitjana R, Oriola J. Exploracion clinica, funcional y molecular de la diabetes tipo MODY en la practica clinica. Endocrinol Nutr. 2004;51(Supl 2):16-21.

5. Bioulac-Sage P, Balabaud C, Bedossa P, Scoazec JY, Chiche L, Dhillon AP, Ferrell L, et al. Pathological diagnosis of liver cell adenoma and focal nodular hyperplasia: Bordeaux update. J Hepatol. 2007;46(3):521-527.

6. Bluteau O, Jeannot E, Bioulac-Sage P, Marques JM, Blanc JF, Bui H, Beaudoin JC, et al. Bi-allelic inactivation of TCF1 in hepatic adenomas. Nat Genet. 2002;32(2):312-315.

7. Pontoglio M, Barra J, Hadchouel M, Doyen A, Kress C, Bach JP, Babinet C, et al. Hepatocyte nuclear factor 1 inactivation results in hepatic dysfunction, phenylketonuria, and renal Fanconi syndrome. Cell. 1996;84(4):575585.

8. Lee YH, Sauer B, Gonzalez FJ. Laron dwarfism and non-insulin-dependent diabetes mellitus in the Hnf-1alpha knockout mouse. Mol Cell Biol. 1998;18(5):30593068.

9. Flodby P, Liao DZ, Blanck A, Xanthopoulos KG, Hallstrom IP. Expression of the liver-enriched transcription factors C/EBP alpha, C/EBP beta, HNF-1, and HNF-4 in 
preneoplastic nodules and hepatocellular carcinoma in rat liver. Mol Carcinog. 1995;12(2):103-109.

10. James H, Foster MD, Thomas A, Donohue MD, Martin M, Berman MD. N Engl J Med. 1978;299:239-241.

11. Reznik Y, Dao T, Coutant R, Chiche L, Jeannot E, Clauin $\mathrm{S}$, Rousselot $\mathrm{P}$, et al. Hepatocyte nuclear factor-1 alpha gene inactivation: cosegregation between liver adenomatosis and diabetes phenotypes in two maturity-onset diabetes of the young (MODY)3 families. J Clin Endocrinol Metab. 2004;89(3):1476-1480.

12. Bacq Y, Jacquemin E, Balabaud C, Jeannot E, Scotto B, Branchereau S, Laurent C, et al. Familial liver adenomatosis associated with hepatocyte nuclear factor 1alpha inactivation. Gastroenterology. 2003;125(5):1470-1475.

13. Frayling TM, Bulamn MP, Ellard S, Appleton M, Dronsfield MJ, Mackie AD, Baird JD, et al. Mutations in the hepatocyte nuclear factor-1alpha gene are a common cause of maturity-onset diabetes of the young in the U.K. Diabetes. 1997;46(4):720-725.

14. Kaisaki PJ, Menzel S, Lindner T, Oda N, Rjasanowski I, Sahm J, Meincke G, et al. Mutations in the hepatocyte nuclear factor-1alpha gene in MODY and early-onset NIDDM: evidence for a mutational hotspot in exon 4. Diabetes. 1997;46(3):528-535.

15. Ellard S. Hepatocyte nuclear factor 1 alpha (HNF-1 alpha) mutations in maturity-onset diabetes of the young. Hum Mutat. 2000;16(5):377-385.

16. Bellanne-Chantelot C, Carette C, Riveline JP, Valero R, Gautier JF, Larger E, Reznik Y, et al. The type and the position of HNF1A mutation modulate age at diagnosis of diabetes in patients with maturity-onset diabetes of the young (MODY)-3. Diabetes. 2008;57(2):503-508.

17. Costa A, Bescos M, Velho G, Chevre J, Vidal J, Sesmilo $\mathrm{G}$, Bellanne-Chantelot $\mathrm{C}$, et al. Genetic and clinical characterisation of maturity-onset diabetes of the young in Spanish families. Eur J Endocrinol. 2000;142(4):380386.

18. Klupa T, Warram JH, Antonellis A, Pezzolesi M, Nam M, Malecki MT, Doria A, et al. Determinants of the development of diabetes (maturity-onset diabetes of the young-3) in carriers of HNF-1alpha mutations: evidence for parent-of-origin effect. Diabetes Care. 2002;25(12):2292-2301.

19. Iwen KA, Klein J, Hubold C, Lehnert H, Weitzel JM. Maturity-onset diabetes of the young and hepatic adenomatosis - characterisation of a new mutation. Exp Clin Endocrinol Diabetes. 2013;121(6):368-371.

20. Palomo E, Ballester MJ , Giralt P, Lopez P. Diabetes de comienzo en la infancia tratada con sulfonilureas. An Pe diatr(Barc).2008;69(6):568-571.

21. Castano L, Estalella I, Rica I. Avances de la genetica en la diabetes monogenica: diabetes MODY. En: Caro E, Lopez-Canti LF, editores. Actualizaciones en Endocrinologia pediatrica. 1.a ed. Madrid: Ergon; 2006. p.141149.

22. Barrio R, Bellanne-Chantelot C, Moreno JC, Morel V, Calle $\mathrm{H}$, Alonso $\mathrm{M}$, Mustieles $\mathrm{C}$. Nine novel mutations in maturity-onset diabetes of the young (MODY) candidate genes in 22 Spanish families. J Clin Endocrinol Metab. 2002;87(6):2532-2539.

23. Brunerova L, Treslova L, Pruhova S, Vosahlo J, Broz J, Lebl J, Andel M. [Glibenclamide instead of insulin: a new chance for MODY 3 type diabetes patients: case report]. Vnitr Lek. 2006;52(3):275-279.

24. Burge MR, Sood V, Sobhy TA, Rassam AG, Schade DS. Sulphonylurea-induced hypoglycaemia in type 2 diabetes mellitus: a review. Diabetes Obes Metab. 1999;1(4):199-206. 